\title{
Letter \\ Type II errors in 'Nurses' prediction of volume status after aneurismal subarachnoid hemorrhage: a prospective cohort study'
} Francis C Dane

\author{
James V Finkbeiner Endowed Chair in Ethics, Saginaw Valley State University, University Center, MI 48710, USA
}

Corresponding author: Francis C Dane, fdane@svsu.edu

Published: 17 February 2009

This article is online at http://ccforum.com/content/13/1/402

(c) 2009 BioMed Central Ltd

See related research by Hoff et al., http://ccforum.com/content/12/6/R153
Critical Care 2009, 13:402 (doi:10.1186/cc7705)
Hoff and colleagues have conducted what could have been an important study regarding nurses' abilities to predict volemic status among patients [1]. Unfortunately, they collected and analyzed their data in a manner inconsistent with accepted statistical procedures. Hoff and colleagues did not incorporate the extent to which the observations for each patient, as well as from each nurse, were correlated. Their conclusions are not appropriate to their data; indeed, their procedures make any reasonable conclusions impossible.

The importance of correcting for correlated data is easily illustrated with the error term for Student's $t$ [2]: $\sqrt{ }\left(S_{X}^{2}+S_{Y}^{2}-2 S_{X Y}^{2}\right)$, wherein $S_{X}^{2}$ refers to variance for variable $X, S_{Y}^{2}$ refers to variance for variable $Y$, and $S_{X Y}^{2}$ refers to covariance (nonstandardized correlation) for variables $X$ and $Y$. Larger correlations produce smaller error terms, which result in larger statistical values and a lower probability of type I error; correlation between observations makes it more likely to obtain a significant difference [3]. Failing to correct an error term appropriately increases the probability of a type II error failure to reject a null hypothesis that should be rejected.

Hoff and colleagues note that they considered their measures to be independent, but their reasons are not relevant to the problems imposed by failing to correct for correlations. Neither variations in a patient's blood volume, the number of nurses making observations, nor large variations in the nurses' estimates alter the facts that multiple observations were obtained from some patients and multiple predictions were made by some nurses. The data were correlated.

Hoff and colleagues finding of low predictive utility may result from the nurses' inability to predict blood volume, it may result from type II error, or it may result from a combination of these two factors. Because we do not know how large the relevant correlations might have been, we are unable to estimate the extent to which the relevant error terms have been compromised. Their failure to keep track of which observations were made by which nurse - however well intentioned with respect to fears concerning quality control - made it impossible to analyze their data appropriately and makes it impossible to draw any conclusions from their results.

However convincingly well written, we know no more about nurses' abilities to predict the blood volume after reading Hoff and colleagues' article than we knew before reading the article. Any investigators tempted to replicate Hoff and colleagues' study are strongly encouraged to find ways of avoiding fears concerning quality control other than collecting data that cannot be analyzed appropriately. A promise of confidentiality comes to mind as one means by which to reduce such fears.

\section{Competing interests}

The author declares that they have no competing interests.

\section{Author's information}

FCD is a Fellow of the Royal Statistical Society and Vice President of the Mid-Michigan Statistical Association, a chapter of the American Statistical Association,

\section{References}

1. Hoff RG, Rinkel GJE, Verweij BH, Algra A, Kalkman CJ: Nurses' prediction of volume status after aneurismal subarachnoid hemorrhage: a prospective cohort study. Crit Care 2008, 12:R153.

2. Gossett WS: The probable error of a mean. Biometrika 1908, 6:1-25.

3. Witte RS, Witte JS: Statistics. 8th edition. New York: John Wiley \& Sons; 2006.

$S_{X}^{2}=$ variance for variable $X ; S_{Y}^{2}=$ variance for variable $Y ; S_{X Y}^{2}=$ covariance (nonstandardized correlation) for variables $X$ and $Y$. 